\title{
Effects of Mobile Learning in Medical Education: A Counterfactual Evaluation
}

\author{
Laura Briz-Ponce ${ }^{1}$ • Juan Antonio Juanes-Méndez ${ }^{1}$. \\ Francisco José García-Peñalvo $^{1}$ • Anabela Pereira ${ }^{2}$
}

Received: 28 February 2016 / Accepted: 31 March 2016/Published online: 20 April 2016

(C) Springer Science+Business Media New York 2016

\begin{abstract}
The aim of this research is to contribute to the general system education providing new insights and resources. This study performs a quasi-experimental study at University of Salamanca with 30 students to compare results between using an anatomic app for learning and the formal traditional method conducted by a teacher. The findings of the investigation suggest that the performance of learners using mobile apps is statistical better than the students using the traditional method. However, mobile devices should be considered as an additional tool to complement the teachers' explanation and it is necessary to overcome different barriers and challenges to adopt these pedagogical methods at University.
\end{abstract}

Keywords Medical education $\cdot$ Mobile devices $\cdot$ mHealth . mlearning $\cdot$ Apps $\cdot$ Methodology $\cdot$ Smartphones $\cdot$ Tablets elearning $\cdot$ ehealth

\section{Introduction}

Currently, undergraduate medical students are living in a Society in which the use of mobile devices is part of the daily routines. In fact, they have reached some limits that it has ever thought before. According to the last report of International Telecommunication Unit [1], it exists in the world around 7.000 million of users with a mobile line. The access to these

This article is part of the Topical Collection on Education and Training

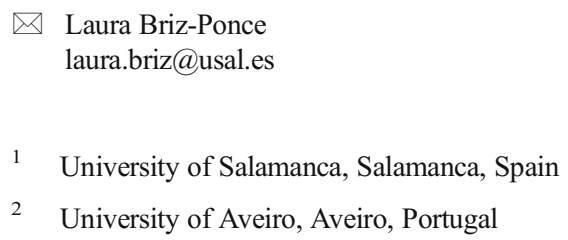

2 University of Aveiro, Aveiro, Portugal

new technologies is becoming easier, which has made most students own a mobile device. According to different surveys conducted in several Universities, there is an increasing number of students with a smartphone or a tablet. For example Jackson [2] reported in his study that $90 \%$ of students $(n=102)$ owned a smartphone and $10 \%$ of them $(n=102)$ owned a tablet. In addition, the Institution EDUCAUSE conducts each year a survey among undergraduate and graduate students regarding the perception of mobile learning in higher education. In its last report [3], they published that around $95 \%(n=1181)$ of students owned a smartphone and $57 \%$ of them $(n=1181)$ owned a tablet. Taking into account only medical students, the figures are very similar. For example in the study conducted at University of Salamanca [4], it revealed that around $93,6 \%(n=124)$ of participants owned a mobile device and 47,6\% owned a tablet.

Due to this increasing and rapidly evolving of technology with mobile devices, the mobile learning is becoming a new trend in the Education Context and particularly in Medicine. Mobile learning has been defined by different authors [5-8]. In effect, El-Hussein \& Cronje (2010) define mobile learning within the context of higher education and they claim that this term is divided in three components: the mobility of the technology, the mobility of the learner and finally, the mobility of the process of learning itself. Other authors suggest that mobile learning is; "any sort of learning that happens when the learner is not at a fixed, predetermined location, or learning that happens when the learner takes advantage of the learning opportunities offered by mobile technologies" [9].

According to all of them, the authors report their own definition of mobile learning as "instructional method that uses mobile devices or mobility as fundamental resources with the objective of teaching or assimilating new concepts".

There are some studies that investigate about the trends of mobile learning [10], the perception of students or teachers 
[11-14], their challenges $[11,15,16]$, benefits $[11,17,18]$ but there are few of them related with the real impact of mobile learning [19-22].

This study tries to cover this gap in order to contribute to the general system of education and try to provide new resources, ideas, models or even patterns that can be implemented at highly regarded Universities or Institutions. Therefore, it conducts an experimental study with medical students at University of Salamanca comparing the results between the use of a mobile app as a tool to learn anatomy and the traditional method of teacher's explanation.

\section{Methodology}

\section{Method}

The research was based on a descriptive-comparative quasiexperimental design [23] and used a mixed methodology predominantly with quantitative data. In fact, considering the quasi-experimental design, the authors used a non-equivalent control group design, as the participants were not assigned randomly [24]. In this case, a pretest and a posttest were performed before and after the treatment in order to measure the homogeneity of the groups.

Besides, it was necessary to take into account the regression effect. This effect measures the natural variations that could be observed on the scores in the pretest and posttest evaluations and they could be attributable to the individual's characteristics itself instead of the result of the experiment. It is important to notice that the investigator can not control these factors. The present research was using an experimental and control group. Kerlinger and Lee [25] claimed that, in this case, if these factors affected the participants, they would affect the participants of both groups, so the differences observed between the groups should be assigned to the experimental manipulation.

\section{Materials}

In order to perform this experiment was necessary to prepare different resources previously. First, it was necessary to select the app to use in the experiment. This was very important and this mobile app had to fulfill the four following requirements:

- It should be available in App Store for iPhone and for iPAD

- It should be suitable for self-study without requiring the intervention of an instructor.

- It should be free or at least accessible for a base fee charge (two euros s or less).

- It should be an app recognized and able to use without any copyright restriction.
Finally, the app Brain System 3D app was selected. This app was developed within the "Image and Technology of the Biomedical Knowledge Centre" (CITEC-B) in Madrid, all together with the "Recognized Investigation Group" of the University of Salamanca: Advanced Visualization Medical Systems (VisualMEd System). This application allows the students to learn about the structure and function of the human brain by interacting with high-resolution rotation 3D images in real time [26].

In addition, it was necessary to prepare the available iPADs for the experiment, installing the app on them. The investigators had 5 iPAds for this research, this number limited the sessions for 10 persons ( 5 for each group).

The experiment was performed in three sessions at Research University of Science Education, which is a faculty of the University of Salamanca, from June of 2014 to November of 2015.

Finally, it was necessary to book two different classrooms previous to the session and have the collaboration of a teacher, who will be in charge of make an anatomy Class with the control group and a brief introduction of the app with the experimental group.

\section{Participants}

This research had the collaboration of 30 students within the range of 18 to 25 years old from the Medical School at University of Salamanca. All the survey respondents were voluntary and the data collected were completely anonymous. The characteristics of the participants are presented in the Table 1. It could be considered that the sample size was relatively small $(N=30)$ although according to the study performed by Mark Mason [27] who analysed the samples of 560 studies, this number is within the normal range of experimental groups.

\section{Procedure}

As it was commented, the sessions were previously prepared. The participants were acquainted that the session would be recorded, that the participation was completely voluntary and they could stop participating at any time. All this information and the activity procedure were provided to the participants in paper in order they could consult anytime if they had any doubt.

As the session was recorded, all the participants should sign a consent information in order to be able to use the photographs and videos for the dissemination and communication of the study. After that, all the participants had to fill a pretest to evaluate their knowledge about anatomy. When they finished, the investigators divided them into two groups randomly and they were lead to different classrooms. The experimental group received a brief introduction of the app the they were going to use during the session by one instructor. The following activity was to execute gradually a guide of tasks provided to the participants. They should follow the different instructions explained in the guide and fill the suitable report to indicate if 
Table 1 Descriptive participants' profile

\begin{tabular}{|c|c|c|c|c|c|}
\hline \multirow[b]{2}{*}{ VARIABLE } & \multirow[b]{2}{*}{ DESCRIPTION } & \multicolumn{2}{|c|}{ Control Group } & \multicolumn{2}{|c|}{ Experimental Group } \\
\hline & & Frequency & $\%$ & Frequency & $\%$ \\
\hline \multirow[t]{2}{*}{ Gender } & Female & 10 & $66,7 \%$ & 12 & $80 \%$ \\
\hline & Male & 5 & $33,3 \%$ & 3 & $20 \%$ \\
\hline \multirow[t]{4}{*}{ Mobile Device } & Smartphone & 6 & $40 \%$ & 9 & $60 \%$ \\
\hline & Only Tablet & 0 & 0 & 0 & 0 \\
\hline & Smartphone and Tablet & 9 & $60 \%$ & 6 & $40 \%$ \\
\hline & None & 0 & $0 \%$ & 0 & $0 \%$ \\
\hline \multirow[t]{4}{*}{ SO Smartphone } & Android & 14 & $93,3 \%$ & 10 & $66,7 \%$ \\
\hline & $\mathrm{iOS}$ & 1 & $6,7 \%$ & 2 & $13,3 \%$ \\
\hline & W8 & 0 & 0 & 1 & $6,7 \%$ \\
\hline & Other & 0 & 0 & 2 & $13,3 \%$ \\
\hline \multirow[t]{5}{*}{ SO Tablet } & Android & 4 & $26,7 \%$ & 2 & $13,3 \%$ \\
\hline & $\mathrm{iOS}$ & 5 & $33,3 \%$ & 2 & $13,3 \%$ \\
\hline & W8 & 0 & $0 \%$ & 1 & $6,7 \%$ \\
\hline & Other & 0 & $0 \%$ & 1 & $6,7 \%$ \\
\hline & None & 6 & $40 \%$ & 9 & $60,0 \%$ \\
\hline \multirow[t]{2}{*}{ Experience apps for learning } & YEs & 6 & $40 \%$ & 1 & $6,7 \%$ \\
\hline & NO & 9 & $60 \%$ & 14 & $93,3 \%$ \\
\hline
\end{tabular}

they complete or not the task. Once they finished the tasks, the third part of the session consisted on the evaluation of the app itself filling out a questionnaire based on 45 items to score five dimensions: Content Quality, Navigation, Credibility, Design or User Interface and Security and Privacy. These factors were selected based on the results of a previous test to measure the acceptance of mobile learning for students [28].

In the meantime, the control group received a traditional class of anatomy by the same instructor and finally both groups performed again the posttest. A graphical description of the procedure is depicted in Fig. 1.

\section{Data analysis}

All data were collected and then computerized using SPSS program v21. Then, a descriptive study was presented and a brief discussion with the data obtained was performed taking into account the relationships between the different variables. The comparative statistical techniques used were the Wilcoxon test and U Mann-Whitney to compare the different scenarios of pre-test and post-test of both groups.

Before applied these comparative techniques, a homogeneous test was employed with the variables of pretest score and both groups. The suitable method in this case was the tStudent test as the variables fulfill the requirements of parametric tests: Normality of Kruskal Wallis $\rho=0,262$ and Levene test $\rho=0,693$. The result of the method $(t=0,834$, $\rho=0,411)$ indicated that there was no evidence enough $(\rho>0,05)$ to fail to reject the null hypothesis that considered both groups (control group and experimental group) homogeneous.

\section{Results}

\section{Overall pre-test scores}

After obtaining the outcome data, it was necessary to analyse the results. First, the authors wanted to compare the baseline

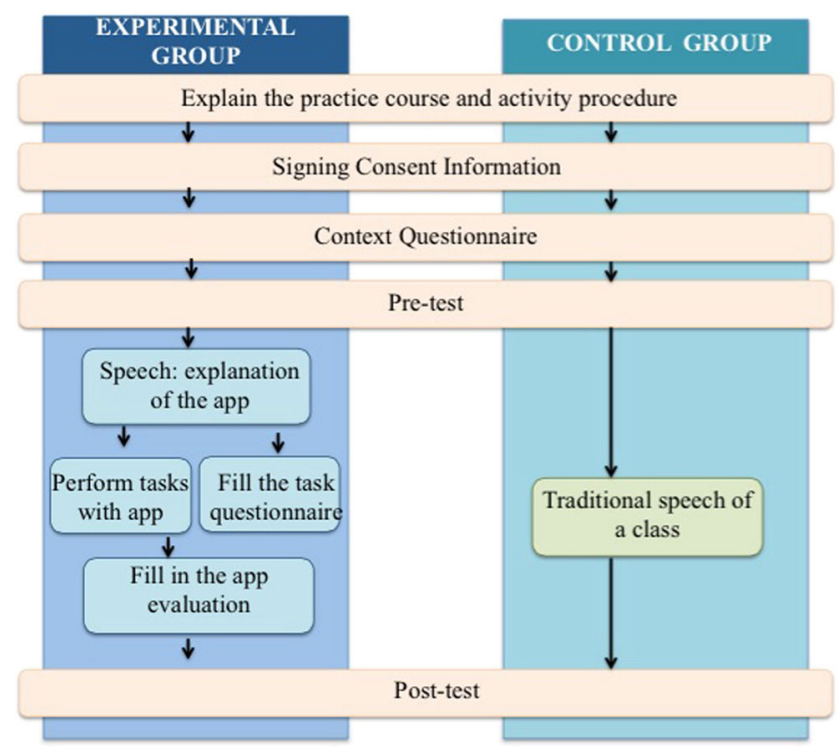

Fig. 1 Detailed flow of the session process 
Table 2 Baseline scores of the two Groups

\begin{tabular}{|c|c|c|c|c|c|c|c|c|}
\hline & \multirow[t]{2}{*}{$\mathrm{N}$} & \multirow[t]{2}{*}{$\dot{\mathrm{X}}$} & \multirow[t]{2}{*}{$\mathrm{Md}$} & \multirow[t]{2}{*}{$\sigma$} & \multirow[t]{2}{*}{$95 \% \mathrm{CI}$} & \multirow[t]{2}{*}{ Interquartile range } & \multicolumn{2}{|c|}{ Mann-Whitney Test } \\
\hline & & & & & & & $\mathrm{U}$ & $\rho$ \\
\hline Control Group & 15 & 2,6667 & 3,0000 & 1,54303 & $1,81-3,52$ & $2,00-4,00$ & 88 & 0,296 \\
\hline Experimental group & 15 & 2,2000 & 2,0000 & 1,37321 & $1,43-2,96$ & $1,00-3,00$ & & \\
\hline
\end{tabular}

The results indicate that at 0,05 level of significance, the pretest score for both groups did not significantly differ $(\rho>0,05)$

scores of the two groups, the control group (conventional methods) and the study group (simulator group). In this case, the non-parametric test was used due to the small number of samples $(N=30)$. Therefore, the most suitable test in this case was the U Mann-Whitney test. This test procedure compares two groups of cases on one variable, the pretest score [29]. The assumption $\left(\mathrm{H}_{0}\right)$ for this test was that the distribution of the scores for the two groups is equal. In other words, both groups had the same level of knowledge. The results are shown in Table 2.

\section{Overall post-test scores}

In this case, the investigators repeated the same method to analyse if the groups after the treatment were equal. The Mann-Whitney $U$ test was performed with the posttest score variable as the dependent variable and the groups (control group and study group) as the independent variable. The results are summarized in the Table 3 . At $\alpha=0,05$, the results indicate that there was evidence enough to fail to reject the null hypothesis to consider both groups to be equal. Therefore, the outcome data suggests that there was a significantly difference in the knowledge of Anatomy $(\rho<0,05)$ between both groups after the experiment.

\section{Comparison pre-test and post-test scores}

Finally, the groups were compared for their pretest and posttest scores. In this case, the analysis must be performed with two-related samples so the Wilcoxon paired test must be used. The results suggested that the change in score did not reach statistical significance in the control group $(Z=-1,414$ and $\rho=0,157>0,05)$. On the contrary, in the experimental group, the outcome revealed a possible statistical significance difference $(Z=-2,158$ and $\rho=0,031)$.

\section{Discussion and conclusion}

This study compares two modalities of learning: on one hand a traditional method based on a teacher's speech and on the other hand a simulator experience based on the use of mobile technologies as an educational app running on an iPad. The results of this experiment suggest that the performance of the learners were better using the app as a supportive tool than using the traditional methods. These results confirm other similar experiments. For example the one conducted at Berry College, USA, [19] with 54 students in an introduction to psychology course. In this case, the students must use an interactive 3-D Brain app or their online course textbook. The results also showed a significant increase in performance from pretest to posttest for the app group on all measures.

Other cases were the one conducted by Jeonju University, South Korea and University of Miami, USA [30] to evaluate the cardiopulmonary assessment skills with mobile applications. They reported that mobile applications could be used as educational tools similarly effective to a traditional human patient simulator.

Other authors, as Ling, Harnish and Shehab [18] sought to demonstrate if the mobile apps could help students' learning of new statistical concepts. They conducted a study with two groups $(N=26)$ and obtained that the participants using mobile app were more confident to learn new materials than the control group. In addition, other investigation in California [20] with undergraduate human anatomy course examined the performance of students analyzing three groups (without an iPAD, with limited access to the iPad and unlimited access

Table 3 Post Test scores of the two Groups

\begin{tabular}{|c|c|c|c|c|c|c|c|c|}
\hline & \multirow[t]{2}{*}{$\mathrm{N}$} & \multirow[t]{2}{*}{$\dot{\mathrm{X}}$} & \multirow[t]{2}{*}{$\mathrm{Md}$} & \multirow[t]{2}{*}{$\sigma$} & \multirow[t]{2}{*}{$95 \% \mathrm{CI}$} & \multirow[t]{2}{*}{ Interquartile range } & \multicolumn{2}{|c|}{ Mann-Whitney Test } \\
\hline & & & & & & & $\mathrm{U}$ & $\rho$ \\
\hline Control Group & 15 & 2,4000 & 2,0000 & 1,40408 & $1,62-3,18$ & $1,00-4,00$ & 59,500 & 0,024 \\
\hline Experimental group & 15 & 3,6000 & 4,0000 & 1,12122 & $2,98-4,22$ & $3,00-5,00$ & & \\
\hline
\end{tabular}


to this device). In this case, the experiment lasted during a semester and the students were evaluated several times. The results and the perceptions of the participants with iPAd were improving with the time.

On the contrary, there are several studies reporting a bad influence of mobile devices over the performance of students. Some authors [31] indicate that increased cell phone use is associated with decreased academic performance. Others [32] report that there are some problems associated with the use of these devices as cost or security and they claim that there is no evidence enough to know if these type of apps are adequate to fulfill the anatomic curriculum concepts. Due to these reasons, it is important to evaluate and assess them.

In summary, the performance score of learners using mobile app were statistical significance better than the students in the control group. Therefore, mobile devices and relevant apps could enhance the student knowledge of a subject giving them additional resources and materials to complement their skills. However, overcoming the barriers and the challenges of adopting these pedagogical methods at University is still necessary. The great amount of different apps, the cost and different technical problems are identified as the major concerns of students to take advantage of this upward trend that it is already part of our lives.

Acknowledgments This research work is made within University of Salamanca PhD Programme on Education in the Knowledge Society.

\section{References}

1. ITU. (2015). ICT Facts \& Figures: The World in 2015.

2. Jackson, L. D. (2013). Is mobile technology in the classroom a helpful tool or a distraction?: A report of university students' attitudes, usage practices, and suggestions for policies. Int. J. Technol. Knowl. Soc. 8:129-140.

3. Chen, B., Seilhamer, R., Bennet, L., \& Bauer, S. (2015). Students' Mobile Learning Practices in Higher Education: A Multi-Year Study. EDUCAUSE Review. Retrieved from http://er.educause. edu/articles/2015/6/students-mobile-learning-practices-in-highereducation-a-multiyear-study

4. Briz-Ponce, L., and Juanes-Méndez, J. A. (2015). Mobile devices and apps, characteristics and current potential on learning. J. Info. Technol. Res. 8(4):26-37. doi:10.4018/JITR.2015100102.

5. El-hussein, M. O. M., and Cronje, J. C. (2010). Defining mobile learning in the higher education landscape research method. $E d$. Technol. Soc. 13:12-21.

6. Chang, C.-K. (2009). Acceptability of an asynchronous learning forum on mobile devices. Behav. Info. Technol. 29(1):23-33. Retrieved from http://eric.ed.gov/?id=EJ882903.

7. Frohberg, D., Göth, C., and Schwabe, G. (2009). Mobile Learning projects - a critical analysis of the state of the art. J. Comput. Assist. Learn. 25(4):307-331. doi:10.1111/j.1365-2729.2009.00315.x.

8. Laouris, Y., \& Eteokleous, N. (2005). We Need an Educationally Relevant Definition of Mobile. Proc mLearn, (June), 1-13. Retrieved from http://citeseerx.ist.psu.edu/viewdoc/download? doi=10.1.1.106.9650\&amp;rep=rep1\&amp;type $=$ pdf
9. Vavoula, G. N. (2005). A Study of Mobile Learning Practices Reference: Category: Verification: Date: Status: Availability: MOBIlearn. Retrieved from https://lra.le.ac.uk/bitstream/2381/ 33326/5/d4.4v1.0_.pdf

10. Prieto, J. C. S., Migueláñez, S. O., and Peñalvo, F. J. G. (2014). Understanding mobile learning: devices, pedagogical implications and research lines. Teoría Educ.: Educ.Y Cultura En La Soc. Info. 15(1):20-42. Retrieved from http://dialnet.unirioja.es/servlet/ articulo? codigo $=4655290$.

11. Toktarova, V. I., Blagova, A. D., Filatova, A. V., and Kuzmin, N. V. (2015). Design and implementation of mobile learning tools and resources in the modern educational environment of university. Rev. Eur. Stud. 7(8):318-324. doi:10.5539/res.v7n8p318.

12. Pullen, D., \& Swabey, K. (2015). Pre-Service Teachers' Acceptance and use of Mobile Learning in Malaysia. Aust. Educ. Comput. 30(1).

13. Sevillano-García, M. L., and Vázquez-Cano, E. (2015). The impact of digital mobile devices in higher education. Educ. Technol. Soc. 18(1):106-118, Eliminar, 2015. Retrieved from http://www. openeducationeuropa.eu/en/article/The-Impact-of-Digital-MobileDevices-in-Higher-Education.

14. Briz-Ponce, L., and García-Peñalvo, F. J. (2015). An empirical assessment of a technology acceptance model for apps in medical education. J. Med. Syst. 39(11):176. doi:10.1007/s10916-015-0352-x.

15. Green, B. L., Kennedy, I., Hassanzadeh, H., Sharma, S., Frith, G., and Darling, J. C. (2015). A semi-quantitative and thematic analysis of medical student attitudes towards M-Learning. J. Eval. Clin. Pract. 21(5):925-930. doi:10.1111/jep.12400.

16. Ferreira, J. B., Klein, A. ., Freitas, A., \& Schlemmer, E. (2013). Mobile learning: Definition, uses and challenges. In L. A. Wankel \& P. Blessinger (Eds.), Cutting-edge Technologies in Higher Education (pp. 47-82). Emerald Group Publishing Limited. doi: 10.1108/S2044-9968(2013)000006D005

17. Ventola, C. L. (2014). Mobile devices and apps for health care professionals: uses and benefits. Pharm. Ther. 39(5):356-364. Retrieved from http://www.ncbi.nlm.nih.gov/pmc/articles/ PMC4029126/.

18. Ling, C., Harnish, D., and Shehab, R. (2014). Educational apps: using mobile applications to enhance student learning of statistical concepts. Human Factors Ergon. Manuf. 24(5):532-543. doi:10. $1002 / \mathrm{hfm}$.

19. Diliberto-Macaluso, K., and Hughes, A. (2016). The use of mobile apps to enhance student learning in introduction to psychology. Teach. Psychol. 43(1):48-52. doi:10.1177/0098628315620880.

20. Raney, M. A. (2015). Dose- and time-dependent benefits of iPad technology in an undergraduate human anatomy course. Anat. Sci. Educ. doi:10.1002/ase.1581.

21. Lee, M. K. (2015). Effects of mobile phone-based app learning compared to computer-based web learning on nursing students: pilot randomized controlled trial. Healthc. Info. Res. 21(2):125133. doi:10.4258/hir.2015.21.2.125.

22. Martin, R., McGill, T., and Sudweeks, F. (2013). Learning anywhere, anytime: student motivators for m-learning. J. Info. Technol. Educ.: Res. 12(1):51-67. Retrieved from http://www. $\mathrm{scopus}$. com/inward/record.ur 1 ? e id $=2-\mathrm{s} 2.0-$ 84877666782\&partnerID=tZOtx3y1.

23. Briz-Ponce, L., Juanes-Méndez, J. A., and García-Peñalvo, F. J. (2015). Synopsis of discussion session on defining a new quality protocol for medical apps. In proceedings of the third international conference on technological ecosystems for enhancing multiculturality-TEEM15. ACM, New York.

24. Salkind, N. J. (1998). Métodos de investigación (3aEd ed.). Mexico: Prentice Hall. Retrieved from https://books.google.es/ books/about/M\%C3\%A9todos de investigaci\%C3\%B3n.html? $\mathrm{id}=3 \mathrm{uIW0vVD63wC \& pgis=1}$

25. Kerlinger, F., and Lee, H. B. (2002). Investigacion Del Comportamiento (Cuarta Edi). McGraw Hill, CHile. 
26. Briz-Ponce, L., Juanes-Méndez, J. A., and García-Peñalvo, F. J. (2014). Analysis of certificated mobile application for medical education purposes. In: Proceedings of the second international conference on technological ecosystems for enhancing multiculturalityTEEM14. ACM, New York, pp. 13-17. doi:10.1145/2669711. 2669871.

27. Mason, M. (2010). Sample Size and Saturation in $\mathrm{PhD}$ Studies Using Qualitative Interviews. Forum Qualitative Sozialforschung / Forum: Qualitative Social Research. Retrieved from http://www.qualitative-research.net/index.php/ fqs/article/view/1428/3027

28. Briz-Ponce, L., Juanes-Méndez, J. A., and García-Peñalvo, F. J. (2015). Description of a session to assess the efectiveness of apps in medical education. In: Gómez Chova, I. C. T. L., and López Martínez, A. (Eds.), Proceedings of the 9th international technology, education and development conference - INTED 2015. IATED Academy, Madrid, pp. 6461-6467.

29. SPSS Inc. (2010). SPSS Statistics Base 17.0 User's Guide. USA. doi:10.2190/L0N6-P489-NR8N-JQ6K

30. Yoo, I.-Y., and Lee, Y.-M., The effects of mobile applications in cardiopulmonary assessment education. Nurse Educ. Today 35(2): e19-e23, 2015. doi:10.1016/j.nedt.2014.12.002.

31. Lepp, A., Barkley, J. E., \& Karpinski, A. C. (2015). The Relationship Between Cell Phone Use and Academic Performance in a Sample of U.S. College Students. SAGE Open, 5(1). doi:10.1177/2158244015573169

32. Lewis, T. L., Burnett, B., Tunstall, R. G., and Abrahams, P. H. (2014). Complementing anatomy education using threedimensional anatomy mobile software applications on tablet computers. Clin. Anat. 27(3):313-320. doi:10.1002/ca.22256. 